\title{
First report of Encyrtid parasitiod, Copidosomyia ambiguous (Subba rao) Hymenoptera: Chalcidoidea: Encyrtidae) on Mallada desjardinsi (Navas) an indigenous predator of Aleurodicus rugioperculatus Martin in India
}

Elango tnau ( $\nabla$ elaento@gmail.com )

Tamil Nadu Agricultural University https://orcid.org/0000-0002-1528-4996

Aravind A

Tamil Nadu Agricultural University

Jeyarajan Nelson

Tamil Nadu Agricultural University

Ayyamperumal $\mathrm{M}$

National Centre for Integrated Pest Management

\section{Research Article}

Keywords: Aleurodicus rugioperculatus, Whitefly, Coconut, Hymenoptera, Rugose, Predator

Posted Date: June 16th, 2021

DOI: https://doi.org/10.21203/rs.3.rs-564661/v1

License: (9) This work is licensed under a Creative Commons Attribution 4.0 International License.

Read Full License 


\section{Abstract}

Aleurodicus rugioperculatus Martin (Hemiptera: Aleyrodidae), commonly known as the rugose spiraling whitefly (RSW), is an invasive pest on coconut palm (Cocos nucifera L) in southern parts of India. To minimize crop losses, we currently employ a biological control agent, i.e., Mallada desjardinsi (Navas), which is an entomophagous predator for RSW. This voracious feeding predator belongs to the Chrysopidae family. However, under natural conditions, Mallada desjardinsi faces severe parasitoid attacks that hinder its multiplication and predating on RSW. In this study, we report the first incidence of Encyrtid parasitoid, Copidosomyia ambiguous (Subba Rao) (Hymenoptera: Chalcidoidea: Encyrtidae) on Mallada desjardinsi, in India.

\section{Introduction}

The Rugose spiraling whitefly (RSW), Aleurodicus rugioperculatus Martin (Hemiptera: Sternorrhyncha: Aleyrodidae), has been invaded India in 2016 causing enormous harm to the coconut crops and other host plants in different states of India viz., Tamil Nadu, Karnataka, Kerala, and Andhra Pradesh (Sundaraj and Selvaraj, 2017). The invasive RSW is highly polyphagous, with 118 hosts belonging to 43 plant families, including economically important crops across the world (Francis et al ., 2016). RSW was found in severe form after 2017 in India's southern states due to deficit rainfall. Increased temperature and reduced humidity are the prime reasons for a flare-up and spread of the pest $A$ rugioperculatus (Josephrajkumar et al., 2018). RSW causes stress to the coconut trees by removing water and nutrients from the leaves and producing honeydew, which covers the lower leaves and results in sooty mold (Shanas et al., 2016). Moreover, in Coconut, there is no recommendation of pesticides for RSW by the Central Insecticide Board and Registration Committee (CIBRC), which is a nodal agency for pesticide recommendation in India. Hence, RSW management was organic by default, and the majority of agricultural practices in the region are mainly natural and based on local resources. Biological control or biological pesticides based on plants or pathogenic microorganisms and specific to the target pest offer an ecologically sound and effective solution to pest problems (Gupta and Dikshit, 2010). The studies to control $A$. rugioperculatus are mostly related to the natural enemies; surveys for biological control agents have found several important natural enemies and other species that collectively provide healthy control of this whitefly pest ${ }^{2}$.

\section{Materials And Methods}

In our experiment, a field survey was undertaken from August 2017 to February 2019 in major Coconut growing districts of Tamil Nadu viz., Coimbatore, Tiruppur, Erode, Theni, Pudukottai, and Kanyakumari to study the natural enemies of $A$. rugioperculatus. We have identified nine species of predators and one species of parasitoid against this new invasive pest. Among all the natural enemies, three predators viz., Mallada desjardinsi, Chrysoperla zastrowi sillemi, and Cryptolaemus montrouzieri was found maximum and also voraciously feeding on RSW, consequently reducing the population. In this regard, for the mass culturing of these predators, coconut field heavily infested with RSW was selected, and fifty grubs and 
pupae of Mallada desjardinsi, Chrysoperla zastrowi sillemi, and Cryptolaemus montrouzieri were collected randomly from the field at a weekly interval from July to December (2020-21). We reared the grubs in the laboratory by enclosing them in the Petri plate (15 cm diameter), having wet filter paper at the bottom, and green cut leaves of Coconut with nymphs of RSW. Young nymphs of RSW were provided for grubs as a food until they reached the adult stage.

\section{Results}

During the field survey, we have identified nine species of predators against this new invasive pest. These predators are naturally available in RSW affected coconut gardens and also in other host plants. Incidentally, we noticed a parasitoid for RSW from the Aphelinidae family, Encarsia guadeloupae. These entomophagous insects may provide an additional opportunity to the Coconut growing farmers of Tamil Nadu to utilize these potential biocontrol agents against invasive RSW. In this mass culturing process of these predators, we find some small tiny parasitoids emerging from pupal cocoons instead of $M$. desjardinsi adults and roaming inside the mass culturing cage of $M$. desjardinsi. The parasitoid was collected, and the collected parasitoids were studied in Central Integrated Pest Management Center, Directorate of Plant Protection Quarantine and Storage, Tiruchirappalli, Tamil Nadu. The analysis revealed that the tiny insects belonged to family Encyrtidae and Ichneumonidae, and both are pupal parasitoids of Neuropteran predator (Hayat, 2006). The ichneumonid parasitoid, Dicrogaster sp., was already reported on the Neuropteran predator. In Encyrtid parasitoid, Copidosomyia ambiguous (Subba Rao) (Hymenoptera: Chalcidoidea: Encyrtidae) was not reported earlier on M. desjardinsi. The Encyrtid, Copidosomyia ambiguous can be diagnosed based on the following characters: Body black except for the following parts: Antennae except for the clava brown, clava pale yellow; mid femora and tibiae, basal part of hind tibiae white; apices of mid tibiae, spurs, mid tarsi pale white to yellow, hind tarsi dark brown. Hind femur fully brown; hind tarsus completely dark brown (scape $9 x$ as long as wide; pedicel less than $0.25 \times$ scape length); funicle segments 1-4 longer than broad, fifth almost quadrate, sixth broader than long, clava longer than the combined lengths of the three funicle segments. Postmarginal vein is very long shorter than the stigmal costal cell broad with two rows of fine setae; the marginal fringe is very short; the mid-tibial spur is very long, slightly shorter than basitarsus (29:34). The distribution of this pupal parasitoid was in Bangladesh, India (Bengaluru and Tamil Nadu). In the present study emergence potential of these pupal parasitoids was studied, and the emergence range of Copidosomyia ambiguous (Subba Rao) adults was observed from 29.17 to 62.50 percent against $M$ desjardinsi in different months from July to December. The maximum emergence was maximum at the first fortnight of July (62.50 percent), followed by August's second fortnight (60.87 percent). A fluctuation in the emergence range of Copidosomyia ambiguous was observed in subsequent months. In the case of Ichnemonid, Dicrogaster $s p$. parasitoid population was minimum compared to Copidosomyia ambiguous. The emergence range of Dicrogastersp. was from 4.35 to 18.18 percent against M. desjardinsi.

\section{Discussion}


Few studies have documented the parasitism on predators by hymenopteran parasitoids. The cryptine ichneumonid genus Dichrogaster has been reported as external idiobionts of chrysopids and hemerobiids in cocoons (Schwarz and Shaw, 2000). Based on the potential foraging studies of $M$. desjardinsi against $R S W$ revealed that a single grub of $M$. desjardinsi was found to consume 929.8 whiteflies stages, both eggs, and nymphal instars during its total larval period of $9.44 \pm 3.91$ days (Elango, 2019). Hence, this neuropteran predator was playing a major role in controlling the population of RSW. Due to these hymenopteran parasitoids, the predator's growth during the pupal stage is arrested, which is helpful for the RSW to increasing their population in the coconut ecosystem. Our study provides evidence that the hymenopteran parasitoids are also playing an indirect role in the multiplication of the RSW population.

\section{Declarations}

\section{Authors' contributions}

KE , SJN and AA performed the idea of this article, and KE and MA wrote the manuscript. The authors read and approved the final manuscript.

\section{Funding}

This work was not supported by any funding agency

\section{Availability of data and materials}

All presented data are original

\section{Ethics approval and consent to participate}

Not applicable

\section{Conflict of Interest}

The authors declare that they have no conflict of interest.

\section{Consent for publication}

I agree to publish this paper in the International Journal of Tropical Insect Science

\section{Code availability}

Not applicable

\section{References}

1. Sundararaj R, Selvaraj K (2017) Invasion of rugose spiraling whitefly, Aleurodicus rugioperculatus Martin (Hemiptera: Aleyrodidae): a potential threat to coconut in India. Phytoparasitica 45:71-74

2. Francis AW, Stock IC, Smith TR, Boughton AJ, Mannion CM, Osborne LS (2016) Host plants and natural enemies of rugose spiraling whitefly (Hemiptera: Aleyrodidae) in Florida. Florida Entomologist 99:150-153 
3. Josephrajkumar A, Chandrika Mohan PS, Prathibha T, Nalinakumari CPR. Nair (2018) Pest Dynamics and Suppression Strategies. In The Coconut Palm (Cocos nucifera L.)-Research and Development Perspectives, pp. 557-634

4. Shanas S, Job J, Joseph T, Anju Krishnan G (2016) First report of the invasive rugose spiraling whitefly, Aleurodicus rugioperculatus Martin (Hemiptera: Aleyrodidae) from the old world. Entomon 41:365-368

5. Gupta S, Dikshit AK (2010) Biopesticides: An ecofriendly approach for pest control. J Biopestic 3:186-188

6. Hayat M (2006) Indian Encyrtidae (Hymenoptera: Chalcidoidea). Department of Zoology. Aligary Muslim University, Aligarh, $496 \mathrm{p}$

7. Elango K (2019) Bio ecology and bio intensive management of Rugose spiralling whiteflyAleurodicus rugioperculatus Martin." Tamil Nadu Agricultural University; Coimbatore, pp 1-145

\section{Figures}



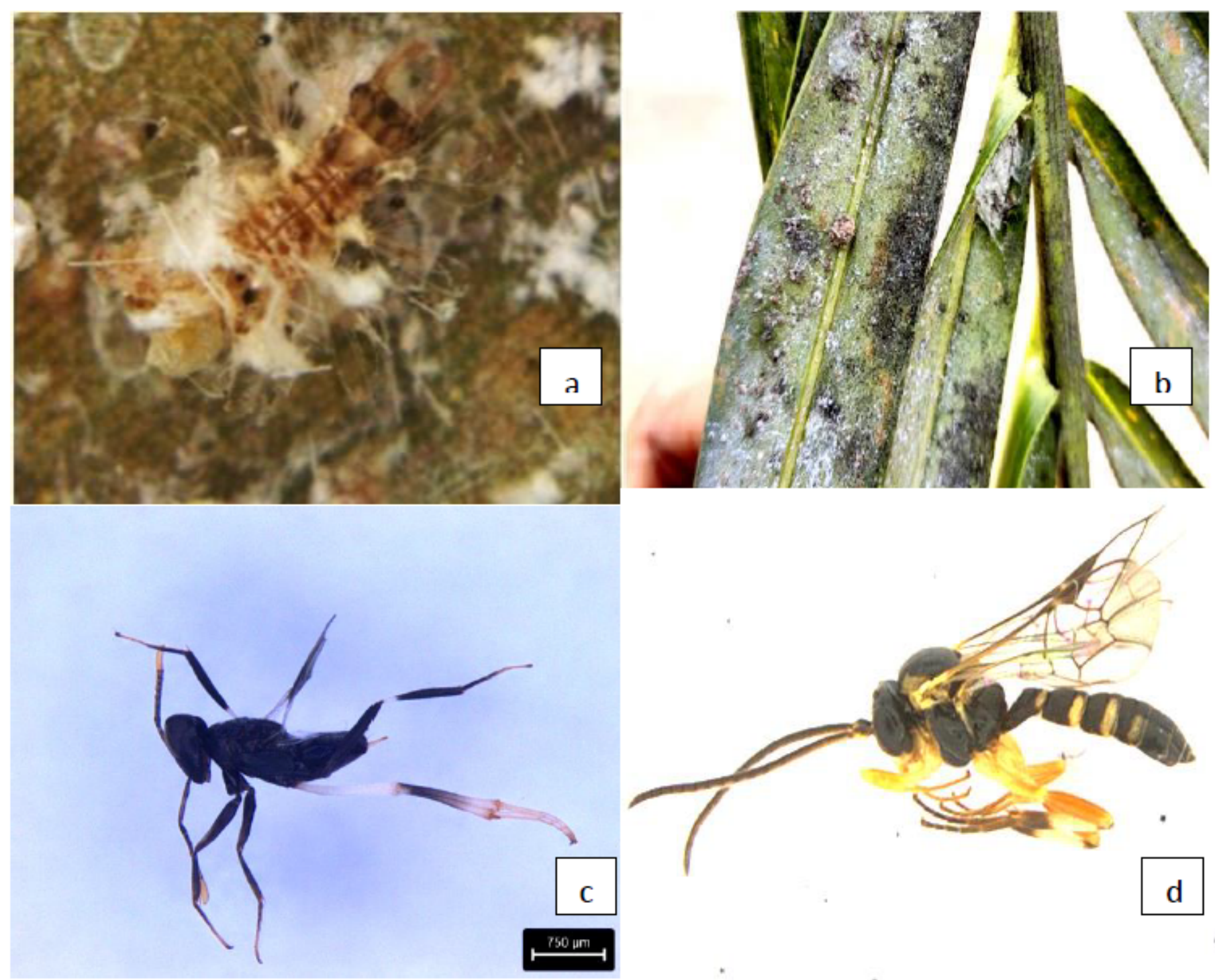

\section{Figure 1}

Neuropteran predator Mallada desjardinsi and their parasitoids, a. Mallada desjardinsi feeding on RSW; b,Mallada desjardinsi on Coconut leaves; C. Copidosomyia ambiguous habitus; $d$. Dicrogaster sp. habitus 